\title{
Exploration of the Second Time Development of ESP Materials: Classroom Practice and Teachers' Roles
}

\author{
Shiping Deng \\ Institute of Linguistics, Shanghai International Studies University, Shanghai, China
}

\begin{abstract}
This study investigates teachers' second time development of ESP materials in the context of ESP curriculum reform in a Chinese university where a newly published series of textbooks are used. Data collected from classroom observations were analyzed to reveal teachers' practice in the second time development of materials. Semi-structured interviews with ESP teachers were conducted to disclose the hidden agendas of teachers by a thorough thematic analysis. Results show that teachers' second time development techniques mainly include omitting the "Researching Task" part, supplementing more "critical thinking" tasks, glancing through the "Reading Strategies" and simplifying the interpretation of discipline-related content. More advanced development strategies such as adding more discipline-related knowledge, changing the instructional sequence, reconstructing or creating certain contents are seldom used. The overall second time development practice indicates that teachers would rather simplify the teaching process than make it meaningful. Inability, laziness, the lack of awareness, and fear of making mistakes are the main causes of teachers' rudimentary development practice. This study then suggests that institutions and teacher educators should offer special programs that can improve teachers' skills in the second time development of teaching materials, take measures to enhance ESP teachers' disciplinary/content knowledge, and enforce rigorous management so as to make the second development of ESP materials more effective and thus improve the quality and efficiency of ESP teaching and learning.
\end{abstract}

Index Terms - the second time development of materials, ESP courses, classroom practice, hidden agendas, suggestions

\section{INTRODUCTION}

A teacher often finds that it is necessary for him/her to adapt provided materials to optimize language learning (Macalister, 2016). This process of material adaptation is also labeled as "the second time development of language materials" to emphasize teachers' innovative roles in the use of already published textbooks (Wang, Yu, Wang, Shi, \& Dong, 2016). The second time development of language materials is rather important to teaching and learning as it is usually an indispensable step for teachers to make their teaching more effective and interesting(Cheng \& Sun, 2011, p. 123). In China, ESP courses have received special attention from the academia and institutions of tertiary education in the past few years in the context of college English course teaching reform. Some local ESP textbooks have been published to meet both teachers' and students' needs. However, there is a relatively small body of literature that is concerned with teachers' second time development of ESP materials. This paper is to therefore to fill this gap by exploring why ESP teachers decided (not) to make certain adjustments/adaptations through a qualitative study in a science and engineering university (which will be addressed as "University Z" in this paper) in China where ESP reform has been implemented for several years. Implications for institutions, teacher educators and teachers are presented to make the second development of ESP materials more effective and thus improve the quality and efficiency of ESP teaching and learning.

\section{METHODOLOGY}

This study sought to answer the following specific research questions:

1. What techniques do teachers use to conduct the second time development of ESP materials in classroom practice?

2. Why do teachers use these techniques? Why don't they use other techniques?

3. What can be done to improve teachers' skills in the second time development of ESP materials?

To address these research questions, qualitative data were collected in the following two ways. Firstly, the researcher observed the online and offline ESP courses taught by teachers in University Z and took field notes which were mainly about the material adaption teachers have made in both real and virtual classrooms. Secondly, the researcher summarized and classified the adaption practice and conducted in-depth interviews with five of the ESP teachers to elicit teachers' hidden ideologies (i.e. why they used or why they did not use certain adapting techniques). 
The university where this research was conducted will be addressed as University $\mathrm{Z}$ in this paper. University $\mathrm{Z}$ is a tertiary institution which features science and engineering disciplines, so there has been an appeal for ESP courses for a long time to make language education conducive to the development of those preponderant disciplines. Since 2015, final decision was made to implement a policy of initiating ESP courses and switching from general English to ESP step by step, for the sake of the institution and the future of the students. ESP courses were soon offered by the college of foreign studies of the university. At that time, the teachers had little experience of ESP teaching, nor did they have any knowledge of the corresponding disciplines (for example, chemical engineering, mechanical engineering, etc.). Initially the teachers collected some materials and designed their lessons by themselves. Two years later the dean launched a textbook editing program to develop some formal ESP materials. Finally a series of ESP textbooks were successfully edited and published by a famous publishing house in China and were introduced to the ESP courses in University Z. This series includes eight ESP textbooks of very different disciplines, but the structure of each textbook is rather similar. There are several units in each book. Each unit contains two sections: Section A includes Pre-reading, Text A, Reading comprehension, Language focus, Critical thinking and Researching task. Among these parts, critical thinking claims to encourage independent thoughts on certain disciplinary topics. The following is a typical example in this part: "Large areas of natural vegetation and forests have been cleared to grow plants for biofuels, which has become a controversial topic. Share your opinion with the class". Researching task is a part aimed at improving academic skills. For example, this part may introduce how to collect data in a research project or how to write an abstract for an academic paper. Section B is designed for supplementary reading, with a part labeled as "Reading Strategies" focusing on different reading skills of disciplinary texts in English and a text (Text B). For instance, students may be required to learn how to identify the structure of a complex sentence in a disciplinary text.

\section{B. Participants}

All the five participants in this research have been teaching general English for more than ten years, but none of them have been teaching ESP for more than five years. The participants' profiles are presented in Table I. They are addressed by codes for ethic consideration. P2 and P5 were also editors of the published textbooks that have been used in their ESP courses.

TABLE I

PARTICIPANTS' INFORMATION

\begin{tabular}{|l|l|l|l|}
\hline Participants & Gender & Title & teaching experiences of ESP \\
\hline P1 & female & $\begin{array}{l}\text { associate } \\
\text { professor }\end{array}$ & 3 years \\
\hline P2 & female & lecturer & 4 years \\
\hline P3 & female & $\begin{array}{l}\text { associate } \\
\text { professor }\end{array}$ & 5 years \\
\hline P4 & female & lecturer & 4 years \\
\hline P5 & male & lecturer & 5 years \\
\hline
\end{tabular}

\section{Data Collection}

With the participants' permission, the researcher attended their offline courses and watched the online MOOCs and recorded the teaching practice in field notes. By making a comparison and contrast between the actual teaching procedures and the contents in the ESP textbooks, the researcher detailed the teachers' second time development of the ESP materials. Teachers' materials development activities or techniques were then analyzed and classified. In order to get a comprehensive image, the researcher also recorded how the teachers adopted and followed the textbooks in the field notes. To reveal the hidden agendas, five ESP teachers were then invited in interviews in which questions about their teaching practice, the adaptation they made to the published ESP materials, and the reasons why they decided (not) to use certain adapting strategies were asked. Each of the participants was interviewed for about twenty minutes. Throughout the interview, all of them were encouraged to tell what they really thought.

\section{Data Analysis}

The researcher conducted thematic analysis of the above-mentioned field notes and in-depth interview data, which had been transcribed into texts and coded word by word in three rounds. Themes emerging from the three rounds of coding were treated as complementary resources. The themes summarized from the field notes of classroom observation clearly presented teachers' second time development of ESP materials while the interview data mainly revealed why they used (or why they did not use) certain adapting techniques.

\section{RESULTS}

\section{A. Teachers' Classroom Practice in the Second Time Development of ESP Materials}

By summarizing what has been discussed in the available literature (Sherin \& Drake, 2009; Cheng \& Sun, 2011; McDonough, Shaw \& Masuhara, 2013; Macalister, 2016; Leufer, Prediger, Mahns, \& Kortenkamp, 2019), techniques of the second time material development mainly include omitting, supplementing, simplifying, modifying, sorting, 
reordering, replacing, reconstructing or creating certain contents. Based on that, the researcher made an analysis of the field notes of classroom observation and categorized the teachers' material development practice. Results indicate that teachers made the second time development of the ESP materials mainly by adopting the following strategies.

\section{Omitting the "Researching Task" part}

The "Researching Task" is a rather important part of this series of ESP materials, which reflects the material editors' attention to students' skills of doing academic research. In the preface of each material, the editorial board highlights the objective of improving academic skills through academic training and learning academic English. This objective is also listed at the beginning of each unit. Therefore, this part is indispensable in the teaching practice. However, classroom observation data reveals that most teachers omitted this part in both offline teaching and the Moocs, or just made it an optional after-class task. The time for teaching and developing academic skills was given to vocabulary learning: in Moocs, teachers spent a lot of time (approximately one fourth of the time spent on a unit) explaining the words with different meanings in general English and English for specific purposes, or dealing with terminology; in offline classrooms, students were even asked to read the new words and expressions after the teacher, which cost a lot of time; teachers also explained rigorously the vocabulary exercises in "reading comprehension" and "language focus" in class. Omitting the "Researching Task" is likely to render the objective of cultivating academic skills an "empty talk".

\section{Supplementing more "Critical thinking" tasks}

"Critical thinking" is a part in which two or three disciplinary questions or topics (usually pertinent to the topic of Text A) are presented as tasks for discussion. Students can enhance their independent thinking on disciplinary issues and improve their ability to express ideas freely in English for specific purposes. Classroom observation results show that teachers usually extended this part by adding another three or four "critical thinking" tasks. Usually the teacher would divide the whole class into several groups and each group was supposed to share viewpoints on the topics. The discussion session would occupy one fourth (or even more) of the time for a unit. It seemed that the discussions were heated, but students told the researcher that the preparation time was so short (as there were so many topics for discussion and presentation) that they could not fully explore each of the questions or topics. Moreover, teachers' comments on the discussions were usually short and not enlightening. Therefore, students were unlikely to deepen their understanding of the discipline-related topics through the "critical thinking" tasks, and they could not get effective feedback to improve their academic English.

\section{Glancing through the "Reading Strategies" part}

The text structure, the writing style, the structure of each sentence, the diction, etc. of texts in ESP courses are all different from those in a general English course. Students who are not familiar with the characteristics of ESP writing may find the articles difficult to read or understand. "Reading Strategies" in this series of ESP materials are actually a critical part aimed at helping students grasp skills of reading the long and difficult discipline-related texts. However, it seemed that teachers reckoned "Reading Strategies" as a part of general English courses, as they just glanced through it by dealing with two or three simple reading comprehension exercises. The exercises they let students do were not different from those in a general English course. From example, the teacher would just analyze the structure of a sentence by picking up the major components such as the subjects, predicates and objects. He/she seldom analyzed the style of the writing from a disciplinary perspective. Therefore, the students were unable to be aware of the reasons why the texts were difficult to read and many of them told the researcher that they felt confused about the purpose of this part because it seemed that all the skills mentioned by the teachers had already been discussed in general college English courses or even in their high school English courses.

\section{Simplifying interpretation of discipline-related contents}

One more feature that emerged from the ESP teachers' second time material development practice was that they tried to simplify their interpretation of the disciplinary knowledge in the texts. Actually, it seems to be safe if one labels the teaching method as "grammar-translation" because the foci in these ESP classes were vocabulary, grammatical analysis of difficult sentences, and translation of the texts. The researcher found that a typical lesson began with the explanation of new words and phrases (as is discussed above), then the teacher(s) wrote down some long and difficult sentences (usually no more than five sentences, which were selected from the texts) and explained a bit. Then much of the time was spent on the literal translation of the texts. Usually it was the teacher(s) who did the translation, but sometimes the students may also be asked to share their opinions. After the translation, a few reading comprehension questions and some language enhancement exercises (e.g. vocabulary exercises such as matching, blank filling, etc.) would be covered. Little time would be left; so the explanation or interpretation of the disciplinary contents was usually shallow.

\begin{tabular}{|lll|}
\hline omitting & modifying & replacing \\
supplementing & sorting & reconstructing \\
simplifying & changing the sequence & creating \\
\hline
\end{tabular}

Figure 1. A spectrum of teachers' second time development of ESP materials 
The results described above reveal the specific techniques the ESP teachers used in their material adapting practice. Inspired by the adaptation spectrum described by Sherin and Drake (2009, p. 487), a spectrum of teachers' second time development of ESP materials is presented in Figure 1 based on the different levels of teachers' innovations in the teaching process.

In this spectrum, teachers' second time material development strategies roughly fall into three different levels based on their agency exercised in the material adapting practice. Compared with omitting, supplementing and simplifying (level 1), teachers exerted more agency when they modified, sorted, or reordered the materials (level 2). And replacing, reconstructing materials or creating new materials (level 3) need more teacher agency than modifying, sorting or reordering. Based on the above analysis of the data collected from classroom observation, what can be seen is that the ESP teachers mainly made level 1 adaptation; the development practice seldom reached level 2 or level 3 . Their development efforts are actually rudimentary, and it can be concluded that the purpose of their efforts is to simplify their teaching instead of making it more effective.

\section{B. The Hidden Agendas in Teachers' Second Time Development of ESP Materials}

In order to find out why the ESP teachers made adaptation at level 1 instead of level 2 or level 3, the researcher conducted in-depth interviews with them to elicit the hidden agendas. By a thematic analysis of the interview data, four major reasons emerged: teachers' poor academic and adapting skills, their unwillingness to change, the lack of awareness of second time development of materials, and the fear of making mistakes due to their insufficient disciplinary knowledge.

\section{Inability}

This section reveals teachers' inability to conduct second time development of ESP materials from two aspects: teachers' poor academic skills and their poor knowledge of material adaptation. All the five teachers who participated in this research mentioned that they omitted "researching task" mainly because of their lack of academic skills. P1, an associate professor who has been teaching for more than 20 years, admitted this:

I am not good at writing academic papers as I have not got systematic academic training. I became an associate professor in 2006, but to be honest, at that time the requirements for academic publication were not difficult to meet. As you know, we are now required to publish in SCI/SSCI indexed journals. I am afraid that I have not published any. I have not got rich experience in academic writing myself; how can I teach "Researching Task"? So in class I just omitted this part.

The above excerpt shows that P1 was unable to teach how to conduct academic research or publish academic papers because the teacher herself could not do this either. This inability deprived her of the confidence in teaching "Researching Task". While this is the main reason why most teachers omitted this part, they also mentioned that their poor knowledge in adaptation was another obstacle to their material development practice. P2 said:

I know little about material adaptation or second development of materials although I participated in the editing of one ESP textbook. I never learned relevant theories. In ESP courses, I usually just follow the textbook. Sometimes I would change something, but I just did that inadvertently.

What P1's and P2 said can be understood as indicators of teachers' incompetence to conduct second time development of ESP materials.

\section{2. "Laziness"}

Another cause of teachers' rudimentary ESP material adaptation practice is their "laziness". The four female teachers all mentioned that they spent a lot of time on family chores, and all the five participants complained that they were hit with a blizzard of workload. P3 directly pointed out:

I am always busy. Actually I feel overwhelmed sometimes. You know, I have to take care of my child. She is now in high school, preparing for the college entrance examination. This is a big deal for my family and me. I have spent a lot of time on her. What's more, I need to teach many different lessons recently. I cannot publish any paper in good academic journals so I have to teach as many courses as possible (to compensate for my poor academic skills). The ESP course is just a small proportion of my work, and I don't think it is necessary for me to conduct any second time development of the ESP materials. You can regard me as a lazy ESP teacher, if you like (smile).

The above remarks show that although teachers are busy, they still can be labeled as "lazy" teachers (at least, lazy ESP teachers). Time famine is, to a certain extent, the stock excuse for their laziness. They are reluctant to exercise any agency in the ESP materials; the ultimate objective is just to complete the teaching task.

\section{Lack of awareness}

Teachers also showed poor awareness of ESP material adaptation, which is another reason why their adapting practice just reached level 1. According to data from the interview, most teachers didn't know they needed to make material adaptation until they were asked by the researcher. P4, who have taught ESP courses for 4 years, said that:

In the first two years, we didn't have any formal textbook. The department director built up a team to search for materials on the Internet. I did not join that team; I just used the materials they gave me. In the next two years, we have got textbooks, which were published by an authoritative publishing house. I thought I could just follow these authoritative books.

ESP teachers believe that published textbooks or the materials assigned by the institution are authoritative, so what they need to do is just to follow. They have not realized the importance of the second time development of materials, as 
is also revealed in P3's remarks:

I think the textbooks are good and enough. If we have to adapt these materials, why do we need to publish the textbooks? Moreover, I believe the textbooks are enough for my ESP students. Many of them only have a low level of English, there is no need to bother them, or myself (by making adaptation).

\section{Fear of making mistakes}

Teachers' fear of making mistakes is another cause of their low level of second time development of ESP materials. Almost all teachers who are now teaching ESP courses were previously general English teachers. They majored mainly in British or American literature, or linguistics or applied linguistics. So few of them had any disciplinary knowledge. Therefore, they showed little confidence in modifying or reconstructing discipline-related materials. P5, the department director, is the only one among the five participants who had once tried to make some adaptation to the materials. However, after some unsuccessful trials, he gave up:

I remembered I had found some supplementary materials in another science book and presented them in my ESP class. But after class one of my students told me that the notion discussed in one material was actually out-of-date and was criticized by many scientists. I felt embarrassed. If I knew that, I could have designed some other discussion activities instead of adding that material. This incident made me realize that I could not make right judgment about materials that are unfamiliar to me. Afterwards, I just followed the textbook. That made me feel safe.

From P5's experience, we can clearly feel the dilemma the ESP teachers are faced with. They may run into difficulties at any time because of the lack of disciplinary knowledge. To them, the second time development of ESP materials is another potential cause of trouble. Therefore, most teachers would choose to "teach off a blackboard" instead of excising their agency.

\section{Measures to Optimize Teachers' SeCOnd Time DeVelopment of ESP MATerials}

In the previous sections, the researcher conducted an investigation into the status quo of the ESP material adaptation practice in a Chinese university, and analyzed the reasons why the adaptation is rudimentary. Based on these findings, this section aims at making some suggestions to help teachers improve their skills in the second time development of ESP materials. As is revealed above, material adaptation is a complex and multifaceted problem; therefore, a package of measures need to be taken into consideration.

First of all, it is suggested that teacher educators should offer special programs to improve teachers' second time material development skills. Apart from making ESP teachers realize the importance of this issue, such programs need to tell ESP teachers what they can actually do and what specific techniques they can use in the adapting practice. Moreover, the programs should guide teachers to make the best use of online resources. For example, it is necessary for teachers to know where they can get cutting-edge and authoritative information of a specific discipline.

Besides, measures to enhance teachers' disciplinary/content knowledge must be taken. It may be difficult for ESP teachers to get a deep and thorough understanding of every aspect of a discipline, but basic knowledge is needed and it is also more likely to be acquired. It would be an easy job for institutions like University Z (where this research was conducted) to bring ESP teachers and disciplinary teachers together. Once a cooperative relationship is formed, ESP teachers can consult their colleagues (i.e. the teachers teaching specific disciplines) when they encounter disciplinary problems. It is also advised that institutions directly offer relevant special training programs to the ESP teachers. Only when they have confidence in their disciplinary/content knowledge can the teachers be confident in the second time development of ESP materials.

In addition, rigorous management system is also needed. On the one hand, it is indispensable to set requirements/yardstick that must be followed by ESP teachers. Teachers can guide students to do academic research or write academic papers only when they can do the same by themselves. To make ESP teachers become experienced researchers, academic study and publication should be defined as an important part in the appraisal system of ESP teachers, and institutions and teacher educators should give priority to academic training. On the other hand, measures should be taken to keep the ESP staff stable. Suppose one teacher is teaching English for material science. He/she should be encouraged to teach the same course for the next few years. As experience accumulates, the teacher would gradually be able to make higher level material adaptation (i.e. the second time development of materials at level 2 or level 3 in Figure 1). Moreover, it is highly advised the ESP teaching team be specialized. In other words, ESP teachers should just focus on ESP courses (instead of teaching both ESP and general English at the same time). Only in this way can these teachers become expert in ESP teaching, and thus become expert in the second time development of ESP materials.

\section{CONCLusions}

By conducting a qualitative study in a Chinese university, this research reveals teachers' practice in the second time development of ESP materials and discloses the hidden agendas from a micro perspective. Possible measures that can be adopted to optimize the second time development of ESP materials are also proposed. As an important way to realize effective, individualized and contextualized teaching, the second time development of language materials deserve more attention from the academia. Suggestions for future studies may include conducting research in other institutions or 
countries to check whether the results will be different and whether there are other hidden discourses to be found. Researchers may also be interested in a diachronic investigation of the ever-changing material adapting practice as a result of the dynamics of all kinds of factors.

\section{ACKNOWLEDGMENTS}

The authors wish to thank the participants for their assistance in this research.

\section{REFERENCES}

[1] Cheng, X., \& Sun, X. (2011). ELT Materials Analysis and Design. Beijing: Foreign Language Teaching And Research Press.

[2] Leufer, N., Prediger, S., Mahns, P., \& Kortenkamp, U. (2019). Facilitators' adaptation practices of curriculum material resources for professional development courses. International Journal of Stem Education, 6. doi:10.1186/s40594-019-0177-0.

[3] Macalister, J. (2016). Adapting and Adopting Materials. In M. Azarnoosh, M. Zeraatpishe, A. Faravani, \& H. R. Kargozari (Eds.), Issues in Materials Development. Rotterdam: Sense Publishers, 57-64.

[4] McDonough, J., Shaw, C., \& Masuhara, H. (2013). Materials and Methods in ELT: A Teacher's Guide (Third Edition). Malden, MA: Blackwell Publishing.

[5] Sherin, M. G., \& Drake, C. (2009). Curriculum strategy framework: Investigating patterns in teachers' use of a reform-based elementary mathematics curriculum. Journal of Curriculum Studies, 41, 4, 467-500.

[6] Wang, D., Yu, Y., Wang, C., Shi, L., \& Dong, L. (2016). The Second Time Development of Materials: From Theory to Practice. Shanghai: Fudan University Press.

Shiping Deng was born in Qingdao, Shandong Province in 1986. He received his master degree in Nanjing Forestry University, China in 2011.

$\mathrm{He}$ is currently a lecturer, and a Ph. D candidate in the Institute of Linguistics at Shanghai International Studies University, China. His research Interest: language teaching, language policy and language planning. 